\title{
Exploration of Methylene Blue Degradation Over ZnO Nanorods Mechanism Using Scavenging Reagents
}

\author{
MONIRA G. GHONIEM ${ }^{1 *}$, SARRA A. TALAB ${ }^{1.2}$, ABUELIZ K. MODW $^{3}$ \\ and KAMAL K. TAHA ${ }^{2}$
}

\begin{abstract}
'Department of Chemistry, College of Science, Imam Mohammad Ibn Saud Islamic University (IMSIU), Riyadh 11432, Saudi Arabia,

${ }^{2}$ College of Applied and Industrial Sciences, University of Bahri, P.O. Box 1 1111, Khartoum 1660, Sudan. ${ }^{3}$ Department of Chemistry, College of Science and Arts at Al-Rass, Qassim University, Saudi Arabia.

${ }^{*}$ Corresponding author E-mail: mghoniem1@gmail.com
\end{abstract}

http://dx.doi.org/10.13005/ojc/370313

(Received: April 02, 2021; Accepted: June 03, 2021)

\section{ABSTRACT}

\begin{abstract}
Hierarchical porous flower-like $\mathrm{ZnO}$ structures containing $\mathrm{ZnO}$ nanorods were successfully synthesized by precipitation process. The structure containing high aspect ratio nanorods was revealed by scanning electron microscopy (SEM). The EDS analysis revealed the $\mathrm{ZnO}$ nanostructures formation as confirmed by the $\mathrm{Zn}$ and $\mathrm{O}$ peaks. The Fourier-transform infrared spectroscopy (FTIR) spectrum indicated the $\mathrm{Zn}-\mathrm{O}$ bond vibrational frequency. The typical hexagonal wurtzite $\mathrm{ZnO}$ nanostructure with $15 \mathrm{~nm}$ crystallite size and the characteristic parameters was perceived from the X-ray diffraction (XRD) data. A $10.13 \mathrm{~m}^{2} . \mathrm{g}^{-1}$ surface area, $10.05 \mathrm{~cm}^{3} / \mathrm{g}$ pore volume and $18.25 \mathrm{~nm}$ pore diameter were estimated using nitrogen adsorption analysis. Bandgap energy of $3.229 \mathrm{eV}$ was calculated from the optical analysis data. Under ultraviolet light irradiation, the prepared nanoparticles has effectively decolorized the methylene blue dye. The reaction obeyed the pseudo-first-order kinetics, and the degradation mechanism was proposed using radicals scavengers to determine the species involved in the photodegradation process such as isopropanol, p-benzoquinone, and dimethyl sulfoxide. The reactive oxygen atom in the mechanism of photodegradation, and the recyclability of $\mathrm{ZnO}$ photocatalysts were studied.
\end{abstract}

Keywords: ZnO NPs, XRD, SEM, MB photodegradation, Recyclability, Scavenging reagents.

\section{INTRODUCTION}

Recently, semiconductor nanomaterials have been the focal point of various research aspects due to their attractive and fascinating optical and electrical properties. Such interesting qualities may mainly be attributed to their size reduction ${ }^{1}$. In particular, $\mathrm{ZnO}$ nanostructures with a large bandgap ( $>3.35 \mathrm{eV}$ ), great excitonic energy (60 $\mathrm{meV}$ ) and are mechanically and thermally stable at ambient conditions. These excellent properties have drawn substantial interest for applications such as electronic and optoelectronic devices and lasers ${ }^{2,3}$ chemical sensing ${ }^{4}$, bio-sensing ${ }^{5}$, biological markers ${ }^{6}$, dye-sensitized solar ${ }^{7}$ and electrochemical cells ${ }^{8}$. Different routes are adopted for $\mathrm{ZnO}$ nanostructures

This is an Open Access article licensed under a Creative Commons license: Attribution 4.0 International (CC- BY). Published by Oriental Scientific Publishing Company @ 2018

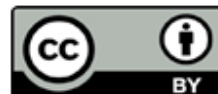


preparation, including chemical vapor deposition ${ }^{9}$, pyrolysis $^{10,11}$, high-temperature decomposition ${ }^{12}$, hydrothermal ${ }^{13}$, sol-gel $\mathrm{I}^{14,15}$ and precipitation ${ }^{16-18}$. Precipitation at low temperature is an inexpensive, scalable facile method for large types of $\mathrm{ZnO}$ nanostructures fabrication. Precipitation procedures have been successfully employed in prior works to synthesize various $\mathrm{ZnO}$ assemblies ${ }^{19}$.

Whether anionic and cationic, industrial dyes are extensively employed in textile; leather processing ${ }^{20}$. Being toxic, carcinogenic and mutagenic to aquatic biological systems, these dyes should be treated before discarding in the runoffs ${ }^{21}$. Still, many types of azo dyes including MB are quite persistent and challenging to degradation methods ${ }^{22}$. Consequently, their interesting photocatalytic and catalytic detoxification have drawn substantial concern in eco-friendly remediation ${ }^{23}$. The photocatalytic demineralization of these hazardous organic dyes is an ecologically preferred approach, as no additional chemicals are needed, and thus, no pollution by-products are produced ${ }^{24}$. During the photodegradation process, where incident radiation with enough energy shines on a semiconductor, it excites electrons from the valence to the conduction band, generating an electron deficiency or hole $\left(\mathrm{h}^{+}\right)$. Oxygen molecules in the aqueous medium react with the electrons to breed strong reducing $\mathrm{O}_{2}$-. ions while the adsorbed water molecules and hydroxide ions react with the $\left(\mathrm{h}^{+}\right)$to generate the strong oxidizing $\cdot \mathrm{OH}$ radicals, that are considered the primary radicals for the photocatalytic degradation ${ }^{25}$.

In the present work, $\mathrm{ZnO}$ nanorods were synthesized through a precipitation process. The nanostructure produced was having $15 \mathrm{~nm}$ size, $3.229 \mathrm{eV}$ bandgap energy, and $10.13 \mathrm{~m}^{2} . \mathrm{g}^{-1}$ surface area. The photocatalyst's ability to decolorize organic dyes was tested using the MB, where the process fitted well with the first order kinetics with a rate constant of $5.9 \times 10^{-3} \mathrm{~min}^{-1}$.

\section{EXPERIMENTAL}

\section{Nanoparticles preparation}

The method reported by Kumar et al., ${ }^{26}$ was followed where an aqueous solution of 1 molar zinc sulfate $(200 \mathrm{~mL}$ ) was added to 2 molar sodium hydroxide solution $(200 \mathrm{~mL})$ dropwise under strong stirring for 12 hours. The colored precipitate obtained was filtered after several times washing (10 times) with deionized water. The precipitate was firstly dried for $2 \mathrm{~h}$ then calcined at $300^{\circ} \mathrm{C}$ for 2 hours.

\section{Characterization of the nanoparticles}

The crystalline structure of the powders was investigated by X-ray powder diffraction (XRD) using Bruker high-resolution diffractometer equipped with Cu-Ka radiation (1.5418 $\AA$ ), operating at $40 \mathrm{kV}$ and $40 \mathrm{~mA}$. Morphological images were recorded by field emission scanning electron microscopy (FE-SEM) using high-resolution Jeol JSM 7600F and transmission electron microscopy (TEM) using JEOL, JEM-2100. The Brunauer-Emmett-Teller (BET) specific surface area was assessed via N2 adsorption-desorption isotherms by employed ASAP 2020 Micromeritics device. The optical properties were determined by means of diffuse reflectance spectroscopy (DRS) using JASECO $\mathrm{V}-770$ spectrophotometer in the wavelength range 300-800 nm. Vibration and bending modes of the all samples were documented by means of Fourier Transform Infrared (FTIR) spectra (JASCO FI-IR 460 spectrometer) in the range $400-4000 \mathrm{~cm}^{-1}$.

\section{Photodegradation using Methylene Blue}

For the degradation MB as a typical contaminant dye, $10 \mathrm{mg} / \mathrm{L}$ was used to inspect the $\mathrm{ZnO}$ photocatalytic activity. Prior to commencing the experiment, $0.050 \mathrm{~g}$ of $\mathrm{ZnO}$ were dispersed in 150 $\mathrm{mL}$ of $\mathrm{MB}$ solution and stirred in the dark for $60 \mathrm{~min}$ to reach equilibrium. Afterwards, the photocatalytic evolution was monitored under $265 \mathrm{~nm}$ ultraviolet illumination. Throughout the photocatalytic course, $(6 \mathrm{~mL})$ of the solution was withdrawn at various times interludes, then centrifuged to clear the solution and then its absorbance was examined between 200 and $700 \mathrm{~nm}$ using UV-Vis spectrophotometer. The photocatalytic degradation percentage was computed the equation ${ }^{27}$.

$M B \%=\frac{C_{0}-C_{t}}{C_{0}} \times 100$

Knowing that $\mathrm{C}_{0}$ and $\mathrm{C}_{t}$ are the initial concentration $(10 \mathrm{mg} / \mathrm{L})$ and time $\mathrm{t} \mathrm{MB}$ concentration, respectively.

\section{Trapping of Reactive Oxygen Species (ROS)}

To study the photocatalytic degradation mechanism of MB over the surface of $\mathrm{ZnO}$ nanoparticles, scavenging reagents were used to 
determine the responsible reactive oxygen species by using isopropyl alcohol (IPA) for scavenging hydroxyl radicals $\left(\mathrm{HO}^{-}\right)^{27,28}$, p-benzoquinone ( $\left.\mathrm{PBQ}\right)$ for scavenging superoxide radicals $\left(\mathrm{O}_{2}^{-}\right)^{27,28}$, disodium ethylenediaminetetra acetic acid $\left(\mathrm{Na}_{2} \mathrm{EDTA}\right)$ for scavenging photogenerated holes $(\mathrm{h}+) 29$, and dimethyl sulfoxide for scavenging photogenerated electrons $\left(\mathrm{e}^{-}\right)^{29}$. The decrease in photocatalytic activity, produced by scavenging reagent, would signify the reactive oxygen species responsible for the photodegradation. $(50.0 \mathrm{mmol} / \mathrm{L})$ concentrations were used except for $\mathrm{PBQ}$, which its optimum concentration was $1.0 \mathrm{mmol} / \mathrm{L}$ for $10.0 \mathrm{mg} / \mathrm{L}$ of $\mathrm{MB}^{29}$.

\section{RESULTS AND DISCUSSION}

\section{XRD analysis}

The XRD pattern of the fabricated NPs (Fig. 1) displays an archetypal XRD configuration of $\mathrm{ZnO}$ crystal pattern as inveterated by $2 \Theta \approx 31.58$, $34.24,36.10,47.32,56.38,62.64,67.82$ and $68.98^{\circ}$ that serially correspond to the (100), (002), (101), (10 2), (110), (103), (200), (112 and, (201) Miller indices indexed to the hexagonal wurtzite $\mathrm{ZnO}^{30}$ and in agreement with the pdf \#36-1451 card for $\mathrm{ZnO}^{31}$. The purity of the prepared sample is confirmed by the absence of any peak due to impurity. The sharp peaks displayed in the pattern designates the synthesis of a highly crystalline material in the nanometer range.

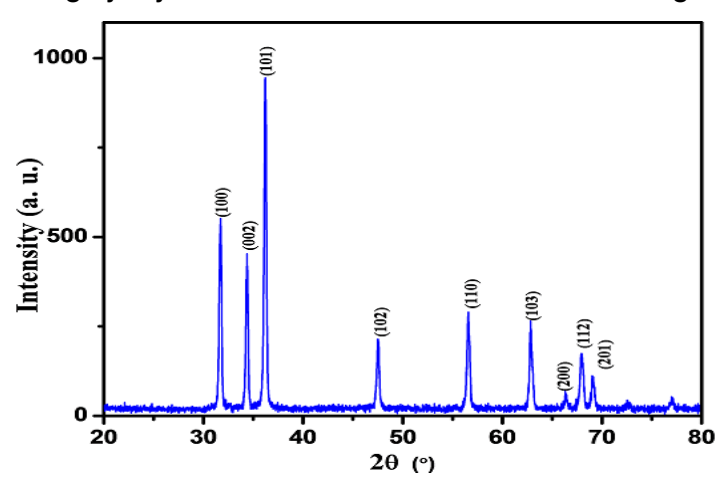

Fig. 1. XRD patterns of ZnONPs

The crystallite sizes (D) of the ZnO NPs was computed according to Scherrer's formula. ${ }^{32}$

$D=\frac{0.90 \lambda}{\beta \cos \theta}$

The terms, $\theta$ and $\beta$ are respectively assigned to the CuKa line $\left(1.5406 A^{\circ}\right)$, the XRD diffraction angle and th (FWHM). The crystallite size of $\mathrm{ZnO}$ was determined using the most intense peak and was found to be $15.32 \mathrm{~nm}$. The lattice parameters and the spacing between planes as designed as a, $c$ and $d$ respectively were calculated using equations $3-5 . .^{33-35}$

$$
\begin{aligned}
& a=\frac{\lambda}{\sqrt{3} \sin \theta_{100}} \\
& c=\frac{\lambda}{\sin \theta_{002}} \\
& \frac{1}{d^{2}}=\frac{4}{3}\left[\frac{\left.h^{2}+h k+k^{2}\right]}{a^{2}}\right]+\frac{l^{2}}{c^{2}} \\
& d=\frac{\lambda}{2 \sin \theta}
\end{aligned}
$$

Where $\Theta_{100}$ and $\Theta_{002}$ correspond the Miller indices (100) and (002) correspondingly, the a and $c$ values are inconsistent with the $\mathrm{ZnO}$ (JCPDS) $\mathrm{card}^{36}$, connoting the synthesis of the nano-size $\mathrm{ZnO}$. Moreover the d-spacing calculated via the theoretical formula (4) and Bragg's law (5) are almost identical (Table 1). The length of the $\mathrm{Zn}-\mathrm{O}$ bond was obtained from the formula (6).

$$
\mathbf{L}=\sqrt{\left[\left(\frac{a^{2}}{3}\right)+(0.5-\mu)^{2} \cdot c^{2}\right]}
$$

Here $(\mu)$ is a factor that describes the magnitude of the atom displacement from its neighbor alongside the $c$ axis, as articulated by (7):

$$
\mu=\frac{a^{2}}{3 c^{2}}+0.25
$$

The obtained $\mathrm{Zn}-\mathrm{O}$ bond value (Table 1 ) is around the previously reported $1.9767 \mathrm{~A}^{\circ}$ value ${ }^{37,38}$. The strain-induced broadening in nanopowder due to crystal imperfection and distortion was calculated using the formula. ${ }^{39}$

$$
\varepsilon=\frac{\beta}{4 \cos \theta}
$$

The micro-strain $\left(\varepsilon_{z}\right)$ along the $c$-axis was estimated using the expression. ${ }^{40}$

$$
\varepsilon_{z}=\frac{c-c_{0}}{c_{0}}
$$

The terms $\mathrm{c}$ and $\mathrm{c}_{0}(5.2066 \AA)$ stand for the computed typical lattice parameters in that order. For the $\mathrm{ZnO}$, the micro-strain is equal to $0.51 \%$ which is tensile strain type that may stimulate the crystallite's orientation along the $\mathrm{z}$-axis ${ }^{41}$. 
Table 1: The ZnO NPs data obtained from the XRD analysis

\begin{tabular}{lccccccccccccccc}
\hline Parameter & $\beta$ & $2 \Theta_{101}$ & $\mathrm{D}(\mathrm{nm})$ & $\mathrm{a}\left(\mathrm{A}^{\circ}\right)$ & $\mathrm{c}\left(\mathrm{A}^{\circ}\right)$ & $\mathrm{c} / \mathrm{a}$ & $\mathrm{d}\left(\mathrm{A}^{\circ}\right)$ & $\mathrm{d}^{*}\left(\mathrm{~A}^{\circ}\right)$ & $\mathrm{u}$ & $\mathrm{Zn}-\mathrm{O}\left(\mathrm{A}^{\circ}\right)$ & $\varepsilon$ \\
\hline Values & 0.5481 & 36.1 & 15.32 & 3.2687 & 5.2335 & 1.6011 & 2.4861 & $\begin{array}{c}2.4903 \\
0.38\end{array}$ & $\begin{array}{c}1.9889 \\
0.0025 \\
\end{array}$ \\
& \pm 0.0003 & \pm 1.44 & \pm 0.75 & \pm 0.163 & \pm 0.210 & & \pm 0.124 & \pm 0.125 & \pm 0.011 & \pm 0.080 & \pm 0.0001 \\
\hline
\end{tabular}

\section{SEM analysis}

The sample's SEM micrograph displayed in Fig.(2a)shows a large hierarchical porous flower-like structure consisting of several flake-like structures under low magnification. At medium magnification (Fig. $2 b$ ), several scattered rod-like nano-structures were covering the flakes' surface.
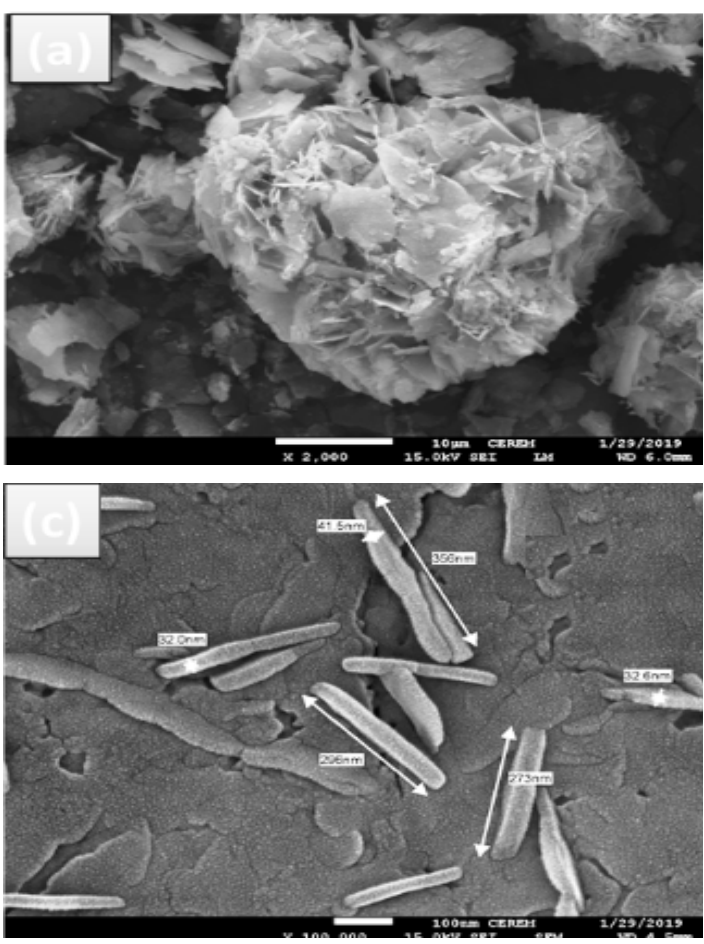

Fig. 2. SEM images at different magnifications (a, b and c) and EDS of ZnO NPs (d)

\section{FTIR bonding analysis}

FTIR spectra of the $\mathrm{ZnO}$ have been recorded to inspect the nature of bonds in the prepared materials, in the range $400-4000 \mathrm{~cm}^{-1}$ (Fig. 3). The peaks at $3462 \mathrm{~cm}^{-1}$ and $1647 \mathrm{~cm}^{-1}$ are respectively due to $\mathrm{O}-\mathrm{H}$ stretching and $\mathrm{O}-\mathrm{H}$ bending vibrations of water molecule ${ }^{42}$. This is due to water molecules' existence on the nanostructures' surface. The band positioned at $2376 \mathrm{~cm}^{-1}$ may indicates $\mathrm{CO}_{2}$ molecules in the air ${ }^{43}$. The peak at $418 \mathrm{~cm}^{-1}$ corresponds to $\mathrm{Zn}-\mathrm{O}$ symmetric bending vibration, and the peak at $604 \mathrm{~cm}^{-1}$ is due to the weak vibration of $\mathrm{Zn}-\mathrm{O}^{44}$. The other peak at $785 \mathrm{~cm}^{-1}$ attributed to $\mathrm{Zn}-\mathrm{S}$ symmetric bending ${ }^{45}$, confirming the EDS finding.
The detailed micrograph Fig. $2 \mathrm{c}$ exhibits high aspect ratio (8.5) nanorods. The (EDS) spectrum (Fig. 2d), snapped from a dense NPs region divulges strong peaks assigned to $\mathrm{Zn}, \mathrm{O}$ atoms, whereas weaker signal form $S$ discernible as well. The existence of the $S$ element may have come from the sulfate in the zinc precursor.
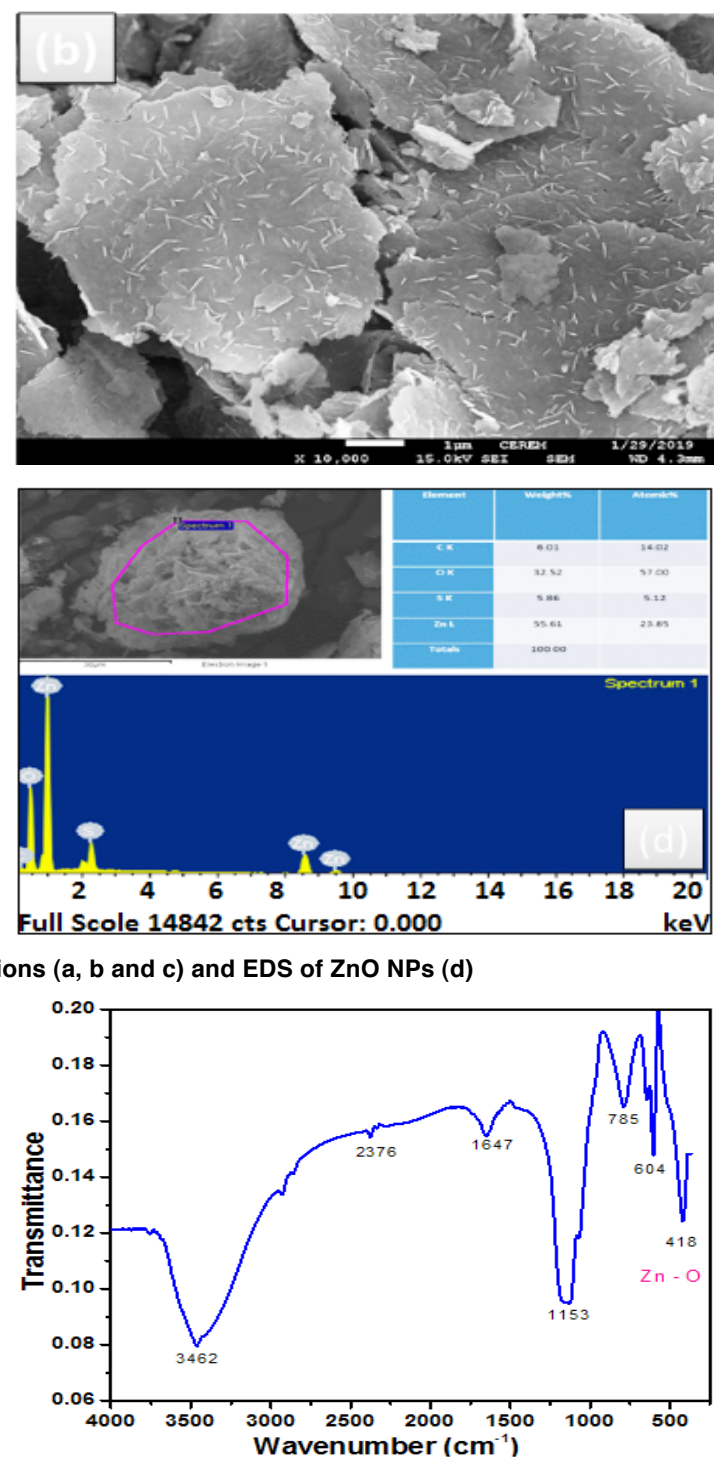

Fig. 3. FTIR spectrum of ZnO NPs

Nitrogen adsorption isotherms

The isotherm profile delivers evidence 
about surface consistency, and it could be generally characterized as displayed in Fig. 4 the nitrogen adsorption-desorption isotherm for the $\mathrm{ZnO}$ sample is type II, as categorized by IUPAC and BrunauerEmmet-Teller (BET). The isotherm shows a type $\mathrm{H}_{3}$ hysteresis loop, distinctive of accumulated particles with mesoporous solids and free monolayermultilayer adsorption. This hysteresis at P/POrange 0.5 and 1 is attributed to condensation in the mesopores related to the inter-particle cavities of the $\mathrm{ZnO}$ structure ${ }^{46}$. The point, at the start of the linear central part of the chart, shows the step where the monolayer coverage is completed and multilayer adsorption starts ${ }^{47}$. The specific surface of 10.13 $\mathrm{m}^{2} \cdot \mathrm{g}^{-1}$ estimatedapplying the BET conventional method is a characteristic of a material with a crystallized material ${ }^{48,49} .10 .05 \mathrm{~cm}^{3} / \mathrm{g}$ and $18.25 \mathrm{~nm}$, are the pore volume and pore diameter, respectively. The particle size distribution Fig. 4 reveals that the average around $30 \mathrm{~nm}$, which is consistent with the isotherm analysis data.

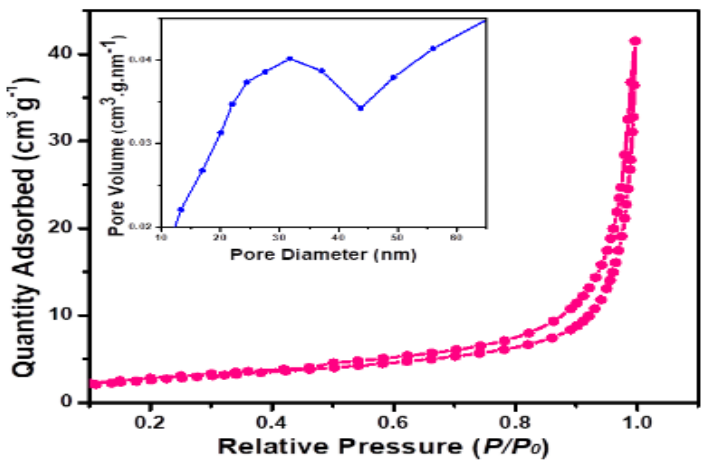

Fig. 4. Adsorption isotherms and pore size distribution

Optical properties and bandgap determination

To examine the optical properties of the ZnO NPs its UV-Visible spectrum was verified and plotted in Fig. 5. The graph exhibits a sharp absorption edge rising at $400 \mathrm{~nm}$, which is shifted to a higher wavelength relative to the standard $\mathrm{ZnO}$ peak ${ }^{50,51}$. The diffuse reflectance spectroscopy (DRS) analysis and (ahv) $)^{2}$ versus hv plots were carried out probe the band energy of ZnO NPs Fig. 5, which was found to be $3.229 \mathrm{eV}$ as estimated applying theTauc equation. ${ }^{52}$

$(\alpha h v)^{1 / n}=A\left(h v-E_{g}\right)$

Here $h, v, a$, and $E_{g}$ are Planck's constant, frequency, absorption coefficient and bandgap energy. $A$ is a constant, and $n$ represents the electron transition type (for directly allowed transitions, $n=1 / 2)$. The Eg for the NPs (3.229eV) is less than the standard $3.37 \mathrm{eV}$ value for $\mathrm{ZnO}^{53}$.

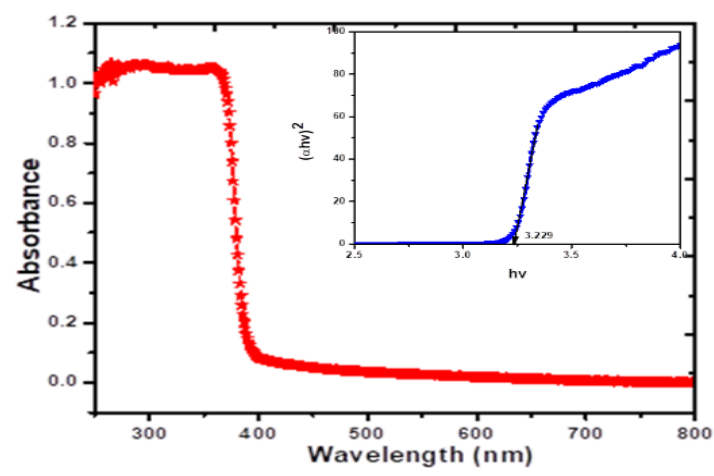

Fig. 5. UV-Vis absorbance and Tauc plots of ZnO NPs

\section{Methylene Blue (MB) photodegradation}

The UV-photodegradation of $10 \mathrm{mg} / \mathrm{L}$ Methylene Blue (MB) dye solution was done to monitor the photocatalytic actions of the ZnO NPs. $30 \mathrm{mg}$ of nanomaterials were sonicated in $100 \mathrm{~mL}$ of $\mathrm{MB}$ solution. Prior to commencing photocatalysis, the solution was stirred for $40 \mathrm{~min}$ in the dark to achieve equilibrium. Then, the photocatalytic evolution was probed under ultraviolet irradiation at $\lambda=265 \mathrm{~nm}$. Throughout the photocatalysis course, $5 \mathrm{~mL}$ of the solution was pipetted at different times intervals, centrifuged to eliminate suspended nanoparticles, and its absorbance was examined between 500 and $800 \mathrm{~nm}$ using UV-Vis spectrophotometer. The proportion of the photocatalytic degradation was assessed using the relation. ${ }^{27}$

$M B \%=\frac{A_{0}-A_{t}}{A_{0}} \times 100$

Where $A_{o}$ and $A_{t}$ are the initial and time $t$ $\mathrm{MB}$ absorbance, respectively.

The photocatalytic action of the $\mathrm{ZnO}$ nanostructures was scrutinized by photodegrading the MB organic contaminant dye. The process was observed by determining the MB absorbance at $\lambda_{\max }=66254$ and different UV radiation time intervals Fig. 6. A gradual decrease in absorbance is evidence of enhanced catalytic efficiency of the ZnO Fig. 6. The data reveals a catalytic competence by the $\mathrm{ZnO}$ photocatalyst Fig. 7 a, which is higher than that shown by $\mathrm{BaTiO}_{3}$ nanoparticles that showed comparable results but with a lower MB concentration ${ }^{54}$. The result is in general similar to many previously reported findings for $\mathrm{Ag} / \mathrm{ZnO}^{55}$ $\mathrm{ZnO} / \mathrm{NiFe}_{2} \mathrm{O}_{4}{ }^{56}$ and $\mathrm{SrFe}_{12} \mathrm{O}_{19}{ }^{57}$ for the degradation of $\mathrm{MB}$. The MB photocatalytic degradation kinetics is 
demonstrated in Fig. 7 b, where the data was plotted according to the pseudo-first kinetics model.

$\ln \left(\frac{C_{0}}{C_{t}}\right)=\ln \left(\frac{A_{0}}{A_{t}}\right)=k t$

The graph demonstrates pseudo-firstorder kinetics as reflected by $\left(R^{2}\right)$ value $(0.97) 58$. The rate constant calculated from the slope is equal to $\mathrm{k}=5.9 \times 10^{-3} \mathrm{~min}^{-1}, \mathrm{t} 1 / 2=117 \mathrm{~min}$ and $\mathrm{Ea}=12.72 \mathrm{~kJ}$. Comparable results showing the consistency of $\mathrm{MB}$ photocatalytic degradation with the first order kinetic model were testified using different nanomaterials ${ }^{56,57,59-61}$.

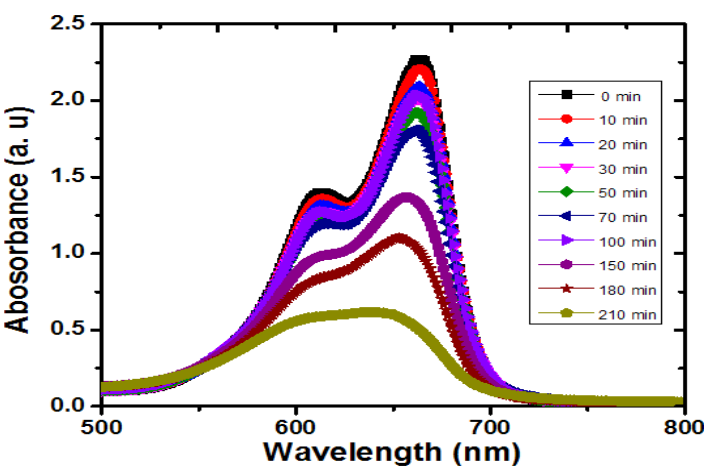

Fig. 6. MB absorbance at different time intervals under UV-light irradiation
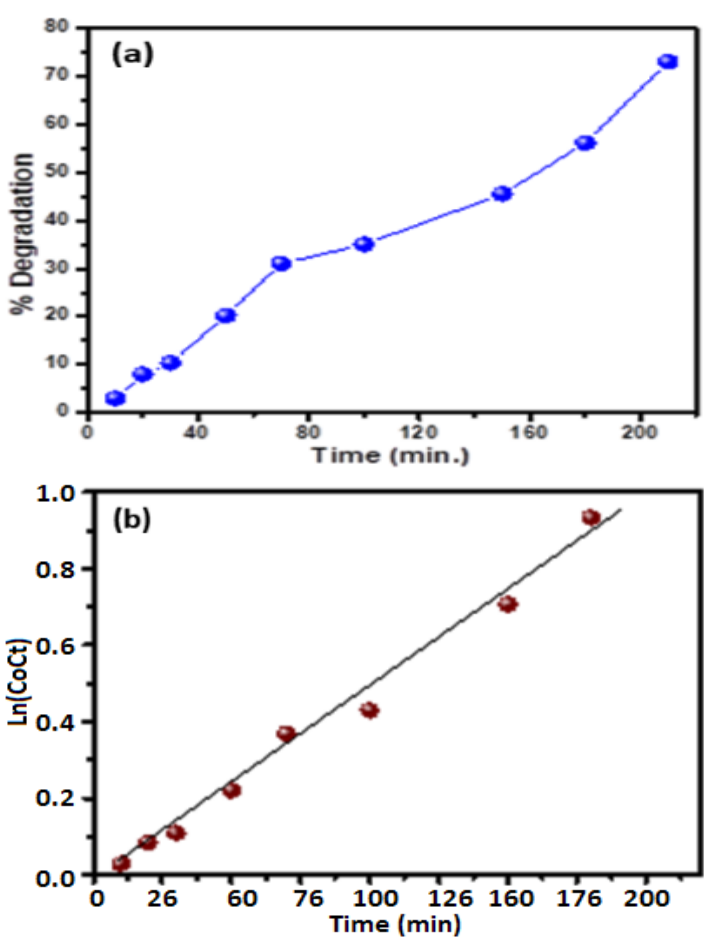

Fig. 7. \%degradation at different time intervals (a) and kinetics of MB Photodegradation (b)

\section{Blocking of Reactive Oxygen Species (ROS)}

The data in Table 2 presents that using isopropanol, as a scavenging reagent for hydroxyl radical did not affect the photodegradation efficiency, regardless of $\mathrm{ZnO}$ nanostructure photocatalyst identity. This observation implied that hydroxyl radical has no role in the photodegradation process of MB. However, the use of para-benzoquinone, for superoxide radical, the photodegradation efficiency was falling down, from $75 \%$ (in the absence of all scavenging reagent) to $45 \%$. This result showed that superoxide radical's minor role in the photodegradation of MB. However, the use of disodium ethylenediaminetetraacetic acid for the photogenerated holes, caused a remarkable reduction in photodegradation efficiency $75 \%$ to $16 \%$ over $\mathrm{ZnO}$. This observation demonstrates the importance of holes direct interaction with $\mathrm{MB}$ on ZnO nanorods' surface in photocatalytic degradation. The role of electrons photogenerated was also examined by using dimethylsulfoxide (DMSO). It was found that they did not dramatically affect photodegradation, which was lowered from $75 \%$ to $54 \%$ over $\mathrm{ZnO}$. This result indicated that $\mathrm{MB}$ photodegradation did not depend on photogenerated electrons over $\mathrm{ZnO}$. Based on scavenging reagents experiments, we conclude that the valence band is where photodegradation of $\mathrm{MB}$ on $\mathrm{ZnO}$ occurs.

Table 2: Effects of scavenging reagents on $M B$ photocatalytic degradation over $\mathrm{ZnO}$ photocatalyst

\begin{tabular}{lccccc}
\hline Scavenging reagent & None & IPA & DMSO & PBQ & Na2EDTA \\
\hline $\begin{array}{l}\text { MB photocatalytic } \\
\text { degradation }\end{array}$ & $75 \%$ & $75 \%$ & $54 \%$ & $45 \%$ & $16 \%$ \\
\hline
\end{tabular}

\section{Photocatalyst Recycling}

We examined the recyclability of $\mathrm{ZnO}$ photocatalysts for reuse in the industrial sector. We found that the photodegradation efficiency decreased from $73 \%$ (first cycle) to $268 \%$ (second cycle) to $42 \%$ (third cycle) over ZnO nanorods (Table 3). This decrease in photodegradation efficiency with the reused photocatalyst could be due to photodegradation products' accumulation on the photocatalyst surface ${ }^{62}$.

Table 3: ZnO photocatalyst recovering for MB photodegradation

\begin{tabular}{lccc}
\hline Cycle number & 1 & 2 & 3 \\
\hline MB photodegradation & $73 \%$ & $68 \%$ & $42 \%$ \\
\hline
\end{tabular}

Mechanism of Photocatalysis

Ultraviolet light irradiation cause electrons 
excitation offering them enough energy to transit from the valence band (VB) to the conduction band (CB) of $\mathrm{ZnO}$ nanoparticles, opening positive holes $\left(\mathrm{h}^{+}\right)$in the $\mathrm{VB}\left(\mathrm{ZnO} \stackrel{U V}{\rightarrow} e_{C B}^{-}+h_{V B}^{+}\right)^{63}$. The strong oxidative species $\mathrm{O}^{-} \cdot$ generated from the electrons and $\mathrm{O}_{2}$ reaction $\left(\mathrm{O}_{2}+\mathrm{e}^{-} \rightarrow \mathrm{O}_{2}^{-\bullet}\right)$ associate with $\mathrm{H}+$ from solution to generate the peroxide $\mathrm{H}_{2} \mathrm{O}_{2} \mathrm{CO}_{2}+$ $\left.2 \mathrm{H}^{+}+\mathrm{e}_{\mathrm{CB}}-\rightarrow \mathrm{H}_{2} \mathrm{O}_{2}\right)^{64}$. The produced $\mathrm{H}_{2} \mathrm{O}_{2}$ then goes through chain reactions with electron to the avail the active $\cdot \mathrm{OH}$ radicals $\left(\mathrm{H}_{2} \mathrm{O}_{2}+\mathrm{e}^{-} \rightarrow \mathrm{OH}^{-}+\cdot \mathrm{OH}\right)$. Similarly $\cdot \mathrm{OH}$ can be created via the $\mathrm{h}^{+}$/ surface adsorbed $\mathrm{H}_{2} \mathrm{O}$ reactions ${ }^{21}$. The degradation process proceeds by the consecutive attacks on the organic dye by $\cdot \mathrm{OH}$ radicals $\left(\mathrm{R}+\cdot \mathrm{OH} \rightarrow \mathrm{R}^{\cdot}+\mathrm{H}_{2} \mathrm{O}\right)$ or $\mathrm{h}^{+}(\mathrm{R}$ $+\mathrm{h}^{+} \mathrm{R} \cdot \bullet^{+} \rightarrow$ products $^{65}$. Fig. 8 is a diagrammatic exemplification for the proposed photodegradation mechanism.

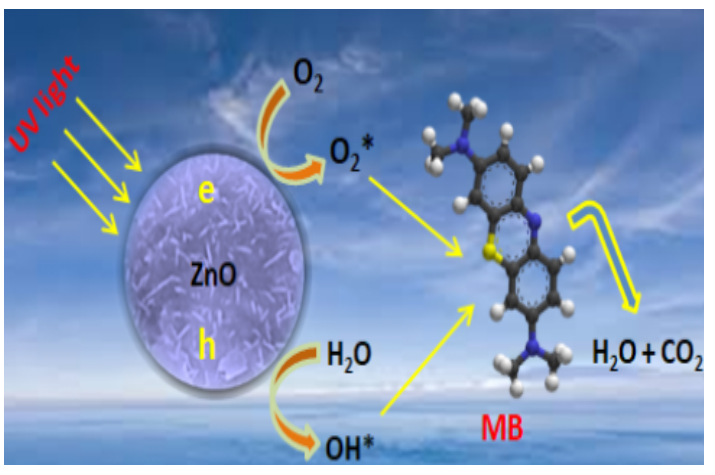

Fig. 8. Elucidation of MB photodegradation CONCLUSION

ZnO NPs of $15 \mathrm{~nm}$ size of archetypal wurtzite structure and cell parameters were efficaciously prepared through a precipitation approach. The SEM images exposed flower-like structures NPs, which were further found to compose primarily of $\mathrm{Zn}$ and $\mathrm{O}$ elements as supported by the EDS analysis. Moreover, the establishment of $\mathrm{Zn}-\mathrm{O}$ bonding was exhibited by the FTIR vibrational frequency assignments. According to the optical examination, the synthesized nanomaterials showed $3.229 \mathrm{eV}$ bandgap. The reaction was pseudo-firstorder kinetics, and the degradation mechanism was proposed using scavenging reagents. They were suggesting that the photodegradation of $\mathrm{MB}$ on $\mathrm{ZnO}$ occurs on its valence band. Also, the recyclability of the photocatalysts was studied. This photocatalyst application for MB degradation marks it an excellent candidate for pollutant dyes detoxification.

\section{ACKNOWLEDGEMENT}

The authors wish to express thanks to Imam Mohamed Ibn Saud Islamic University, where this work has been done.

\section{Conflicts of Interest}

The authors certify that they have NO affiliations with or involvement in any organization or entity with any financial interest or non-financial interest in the subject matter or materials discussed in this manuscript.

\section{REFERENCES}

1. Iqbal, J.;Abbasi, B.A.; Mahmood, T.; Kanwal, S.; Ahmad, R.; Ashraf, M., Plantextract mediated green approach for the synthesis of ZnONPs: characterization and evaluation of cytotoxic, antimicrobial and antioxidant potentials. J. Mol. Struct., 2019. 1189, 315-327. https://doi. org/10.1016/j.molstruc.2019.04.060.

2. R. Bomila.; S. Suresh, and S. Srinivasan, Synthesis, characterization and comparative studies of dual doped $\mathrm{ZnO}$ nanoparticles for photocatalytic applications, Journal of Materials Science: Materials in Electronics 2019, 30, 582-592.

3. Khan, M.M.; Saadah, N.H.; Khan, M.E.; Harunsani, M.H.; Tan, A.L.; Cho, M.H.; Potentials of Costus woodsonii leaf extract in producing narrow band gap
ZnO nanoparticles. Mater. Sci. Semicond. Process., 2019, 91, 194-200. https://doi.org/ 10.1016/j.mssp.2018.11.030.

4. Huang, J.; Wu,Y.; Gu, C.; Zhai, M.; Yu, K.; Yang, M.; and Liu, J.; Large-scale synthesis of flowerlike $\mathrm{ZnO}$ nanostructure by a simple chemical solution route and its gas-sensing property. Sensors and Actuators B: Chemical., 2010, 146(1),206-212.

5. Xia, C.; Wang, N.; Lidong, L.; and Lin, G.; Synthesis and characterization of waxberrylike microstructures $\mathrm{ZnO}$ for biosensors. Sensors and Actuators B: Chemical., 2008, 129(1), 268-273.

6. Bruchez, M.; Moronne, M.; Gin, P.; Weiss, S., and Alivisatos, P., Semiconductor nanocrystals as fluorescent biological labels. Science., 1998, 281(5385), 2013-2016. 
7. Lee, D.; Bae, WK.; Park, I.; Yoon, DY., and Lee, S., Transparent electrode with $\mathrm{ZnO}$ nanoparticles in tandem organic solar cells. Solar Energy Materials and Solar Cells., 2011, 95(1), 365-368.

8. Marina Bandeira a,b.; Marcelo Giovanela b.; Mariana Roesch-Ely b.; Declan M. Devine a.; Janaina da Silva Crespo.; Green synthesis of zinc oxide nanoparticles: A review of the synthesis methodology and mechanism of formation, Sustainable Chemistry and Pharmacy., 2020, 15, 100223.

9. Muccillo, E.; S. Tadokoro, and R. Muccillo, Physical characteristics and sintering behavior of $\mathrm{MgO}$-doped $\mathrm{ZrO}_{2}$ nanoparticles. Journal of Nanoparticle Research., 2004, 6(2), 301-305.

10. Yu, W.; X. Li, and X. Gao, Catalytic synthesis and structural characteristics of high-quality tetrapod-like $\mathrm{ZnO}$ nanocrystals by a modified vapor transport process. Crystal growth \& design., 2005, 5(1), 151-155.

11. Roshitha, S.S.; Mithra, V.; Saravanan, V.; Sadasivam, S.K.; Gnanadesigan, M., Photocatalytic degradation of methylene blue and safranin dyes using chitosan zinc oxide nano-beads with Musa X paradisiaca L. pseudo stem. Bioresour. Technol. Rep., 2019. 5, 339-342. https://doi.org/10.1016/j. biteb.2018.08.004.

12. Liewhiran, C.; S. Seraphin and S. Phanichphant, Synthesis of nano-sized $\mathrm{ZnO}$ powders by thermal decomposition of zinc acetate using Broussonetia papyrifera (L.) Vent pulp as a dispersant. Current Applied Physics., 2006, 6(3), 499-502.

13. Liu, B. and H.C. Zeng, Hydrothermal synthesis of $\mathrm{ZnO}$ nanorods in the diameter regime of $50 \mathrm{~nm}$. Journal of the American Chemical Society., 2003, 125(15), 4430-4431.

14. S. Sandeep Arya.; Prerna Mahajan.; Sarika Mahajan.; Ajit Khosla.; Ram Datt.; Vinay Gupta.; Sheng-Joue Young and Sai Kiran Orugant, Review-Influence of Processing Parameters to ControlMorphology and Optical Properties of Sol-Gel Synthesized ZnONanoparticle, ECS Journal of Solid State Science and Technology., 2021,10023002.

15. Peng, W.; Qu, SC.; Cong, GW and Wang, ZG.; Structure and visible luminescence of $\mathrm{ZnO}$ nanoparticles. Materials science in semiconductor processing., 2006, 9(1), 156-159.

16. ManjunathaRL.; Usharani KVand Dhananjay $\mathrm{Nai}$, Synthesis and characterization of ZnO nanoparticles: A review Journal of Pharmacognosy and Phytochemistry., 2019, 8(3), 1095-1101E-ISSN:2278-4136P-

17. Li, C.; Yu, Z.; Fang, S.; Wang, H.; Gui, Y.; and $\mathrm{Xu}$, J., Preparation and performance of $\mathrm{ZnO}$ nanoparticle aggregation with porous morphology. Journal of Alloys and Compounds., 2009, 475(1), 718-722.

18. Kanitta Phongarthit.; Pongsaton Amornpitoksuk and Sumetha Suwanboon, Synthesis, characterization, and photocatalytic properties of $\mathrm{ZnO}$ nanoparticles prepared by a precipitation-calcination method using a natural alkaline solution, Mater. Res. Express., 2019, 6(4), 045501.

19. Sepulveda-Guzman, S.; Reeja-Jayan, B.; Rosa de la, E.; Torres-Castro, A.; GonzalezGonzalez, V., and Jose-Yacaman, M., Synthesis of assembled $\mathrm{ZnO}$ structures by precipitation method in aqueous media. Materials Chemistry and Physics., 2009. 115(1), 172-178.

20. Wang, W.; Tadé, M.O.; and Shao, Z.; Research progress of perovskite materials in photocatalysis-and photovoltaics-related energy conversion and environmental treatment. Chemical Society Reviews., 2015. 44(15), 5371-5408.

21. Wu, G. and Xing, W., Fabrication of ternary visible-light-driven semiconductor photocatalyst and its effective photocatalytic performance. Materials Technology., 2018, 1-9.

22. Narayanan, K.B. and Sakthivel, N., Synthesis and characterization of nano-gold composite using Cylindrocladium floridanum and its heterogeneous catalysis in the degradation of 4-nitrophenol. Journal of hazardous materials., 2011, 189(1-2), 519-525.

23. Badr, Y. and Mahmoud, M., Photocatalytic degradation of methyl orange by gold silver nano-core/silica nano-shell. Journal of Physics and Chemistry of Solids., 2007, 68(3), 413-419.

24. Ajmal, A.; Majeed, I.; Malik, RN.; Idriss, H. , and Nadeem, MA., Principles and mechanisms of photocatalytic dye degradation on $\mathrm{TiO}_{2}$ based photocatalysts: a comparative overview. $R S C$ Advances, 2014, 4(70), 37003-37026. 
25. Ibhadon, A and Fitzpatrick, P., Heterogeneous photocatalysis: recent advances and applications. Catalysts., 2013, 3(1), 189-218.

26. Kumar, S.S.; Venkateswarlu, P, Rao, VR., and Rao, GN., Synthesis, characterization and optical properties of zinc oxide nanoparticles. International Nano Letters., 2013, 3(1), 30.

27. Meng, A.; Xing, J.; Li, Z., and Li, Q., Cr-doped ZnO nanoparticles: Synthesis, characterization, adsorption property, and recyclability. ACS applied materials \& interfaces., 2015, 7(49), 27449-27457.

28. Chang, J.S.; Strunk, J.; Chong, M.N.; Poh, P.E. and Ocon, J.D. Multi-dimensional zinc oxide $(\mathrm{ZnO})$ nanoarchitectures as efficient photocatalysts: What is the fundamental factor that determines photoactivity in $\mathrm{ZnO}$, Journal of hazardous materials., 2020, 381, 120958.

29. Shtarev, D.; Shtareva, A.; Blokh, A.; Goncharova, P and Makarevich, K. On the question of the optimal concentration of benzoquinone when it is used as a radical scavenger. Applied Physics A., 2017, 123, 602.

30. Zak, A.K.; Razali, R.; Abd Majid, WH., and Darroudi, M., Synthesis and characterization of a narrow size distribution of zinc oxide nanoparticles. International journal of nanomedicine., 2011, 6, 1399.

31. Swarthmore, P., Powder diffraction file, joint committee on powder diffraction standards. International Center for Diffraction data. Card, 1972, 3, 0226.

32. Barrett, C.S., Structure of metals: McGrawHill Book Company, Inc.; New York., 1943.

33. Seetawan,U.; Jugsujinda,S.; Seetawan,T.; Ratchasin, A.; Euvananont, C.; Junin, C.; Thanachayanont, C.; Chainaronk, P. Effect of calcinations temperature on crystallography and nanoparticles in $\mathrm{ZnO}$ disk. Materials Sciences and Applications., 2011, 2(09), 1302.

34. Pandiyarajan, T. and B. Karthikeyan, Cr doping induced structural, phonon and excitonic properties of ZnO nanoparticles. Journal of Nanoparticle Research., 2012, 14(1), 647.

35. Pal, U.; Garcia Serrano a, J.; Santiago, P.; Gang Xiong, Ucer, K. B.; Williams, R.T. Synthesis and optical properties of $\mathrm{ZnO}$ nanostructures with different morphologies. Optical Materials., 2006, 29(1), 65-69.

36. Chung, F.H.; Quantitative interpretation of X-ray diffraction patterns of mixtures.
II. Adiabatic principle of X-ray diffraction analysis of mixtures. Journal of Applied Crystallography., 1974, 7(6), 526-531.

37. Modwi, A.; Abbo, M.; Hassan, E; Taha, K.; Khezami, L.; Houas, A, Influnce of annelling temperature on the properties of $\mathrm{ZnO}$ synthesid via 2.3. dihydroxysuccinic acid using flash sol-gel method. Journal of ovonic research, 2016, 12(2).

38. Taha, K.; M'hamed, $\mathrm{M}$ and Idriss, $\mathrm{H}$. Mechanical fabrication and characterization of zinc oxide $(\mathrm{ZnO})$ nanoparticles. J. Ovon. Res., 2015, 11(6), 271-276.

39. Mote, V.; Purushotham, $\mathrm{Y}$ and Dole, B. Williamson-Hall analysis in estimation of lattice strain in nanometer-sized $\mathrm{ZnO}$ particles. Journal of Theoretical and Applied Physics., 2012, 6(1), 6.

40. Karthika, K. and Ravichandran, K. Tuning the microstructural and magnetic properties of $\mathrm{ZnO}$ nanopowders through the simultaneous doping of $\mathrm{Mn}$ and $\mathrm{Ni}$ for biomedical applications. Journal of Materials Science \& Technology., 2015, 31(11), 1111-1117.

41. Snega, S.; Ravichandran, K.; Baneto, M.; Vijayakumar, S., Simultaneous enhancement of transparent and antibacterial properties of $\mathrm{ZnO}$ films by suitable $\mathrm{F}$ doping. Journal of Materials Science \& Technology., 2015, 31(7), 759-765.

42. Anbuselvan, D. and S. Muthukumaran, Defect related microstructure, optical and photoluminescence behaviour of $\mathrm{Ni}, \mathrm{Cu}$ codoped ZnO nanoparticles by co-precipitation method. Optical Materials., 2015, 42, 124-131.

43. Abdelouhab, Z.A.; Djouadia, D.; Chelouchea, A.; Hammichea, L.; Touam, T., Effects of precursors and caustic bases on structural and vibrational properties of $\mathrm{ZnO}$ nanostructures elaborated by hydrothermal method. Solid State Sciences., 2019, 89, 93-99.

44. Devi, P.G. and A.S. Velu, Structural, optical and photoluminescence properties of copper and iron doped nanoparticles prepared by co-precipitation method. Journal of Materials Science Materials in Electronics., 2016. 27(10), 10833-10840.

45. Roychowdhury, A.; Pati,S.; Kumar,S.; Das,D., Effects of magnetite nanoparticles on optical properties of zinc sulfide in fluorescentmagnetic $\mathrm{Fe}_{3} \mathrm{O}_{4} / \mathrm{ZnS}$ nanocomposites. Powder Technology., 2014, 254, 583-590. 
46. Mercera, P.; Van Ommen,J.; Doesburg,E.; Burggraa, A. Ross, J., Zirconia as a Support for Catalysts: Evolution of the Texture and Structure on Calcination in Air. Applied catalysis., 1990, 57(1), 127-148.

47. Sing, K.S., Reporting physisorption data for gas/solid systems with special reference to the determination of surface area and porosity (Recommendations 1984). Pure and applied chemistry., 1985, 57(4), 603-619.

48. Azouaou, N.; Sadaoui, Z.; Djaafri, A.; Mokaddem, H., Adsorption of cadmium from aqueous solution onto untreated coffee grounds: Equilibrium, kinetics and thermodynamics. Journal of Hazardous Materials., 2010, 184(1), 126-134.

49. Miretzky, P., C. Munoz and E. CantoralUriza, $\mathrm{Cd}^{2+}$ adsorption on alkaline-pretreated diatomaceous earth: equilibrium and thermodynamic studies. Environmental Chemistry Letters., 2011, 9(1), 55-63.

50. Karlsson, M.E.; Mamie,Y.; Calamida,A.; Gardner,J.; Ström,V.; Pourrahimi,A. and Olsson, R., Synthesis of zinc oxide nanorods via the formation of sea urchin structures and their photoluminescence after heat treatment. Langmuir., 2018, 34(17), 5079-5087.

51. Xu, T.; Zhang, L.; Cheng, H.; Zhu, Y., Significantly enhanced photocatalytic performance of $\mathrm{ZnO}$ via graphene hybridization and the mechanism study. Applied Catalysis B: Environmental., 2011. 101(3-4), 382-387.

52. Tauc, J., Optical properties and electronic structure of amorphous $\mathrm{Ge}$ and Si. Materials Research Bulletin., 1968, 3(1), 37-46.

53. Ridha, N.J.; Haji Jumali, M.; Umar, A and Alosfur, F. Defects-controlled $\mathrm{ZnO}$ nanorods with high aspect ratio for ethanol detection. Int. J. Electrochem. Sci., 2013, 8, 4583-4594.

54. Kappadan, S.; Gebreab, T.; Thomas, S.; Kalarikkal, N.; Tetragonal $\mathrm{BaTiO}_{3}$ nanoparticles: an efficient photocatalyst for the degradation of organic pollutants. Materials Science in Semiconductor Processing., 2016. 51, $42-47$.

55. Rafaie, H.; Nor, R.; Azmina, M.; Ramli, N., and Mohamed, R., Decoration of $\mathrm{ZnO}$ micro-structures with $\mathrm{Ag}$ nanoparticles enhanced the catalytic photodegradation of methylene blue dye. J Environ Chem Eng., 2017, 5, 3963-3972.

56. Adeleke, J.; Theivasanthi, T.; Thiruppathi, M.; Swaminathan, M.; Akomolafe, T.; Alabi,
A.; Photocatalytic degradation of methylene blue by $\mathrm{ZnO} / \mathrm{NiFe}_{2} \mathrm{O}_{4}$ nanoparticles, Applied Surface Science., 2018, 455, 195-200,

57. Mishra, D.D. and G. Tan, Visible photocatalytic degradation of methylene blue on magnetic $\mathrm{SrFe}_{12} \mathrm{O}_{19}$. Journal of Physics and Chemistry of Solids., 2018, 123, 157-161.

58. Sopajaree, K.; QASIM, S.; BASAK, S. and RAJESHWAR, K. An integrated flow reactor-membrane filtration system for heterogeneous photocatalysis. Part I: Experiments and modelling of a batchrecirculated photoreactor. Journal of applied electrochemistry., 1999, 29(5), 533-539.

59. Zhang, T.; Oyama, T.; Aoshima, A.; Hidaka, $\mathrm{H}$, Zhao, J.; Serpone, N., Photooxidative $\mathrm{N}$-demethylation of methylene blue in aqueous $\mathrm{TiO}_{2}$ dispersions under UV irradiation. Journal of Photochemistry and Photobiology A: Chemistry., 2001, 140(2), 163-172.

60. Abbaslou, R.M.; V. Vosoughi, and A.K. Dalai, Comparison of nitrogen adsorption and transmission electron microscopy analyses for structural characterization of carbon nanotubes. Applied Surface Science., 2017, 419, 817-825.

61. Vig, A.; Gupta, A. and Pandey, O., Efficient photodegradation of methylene blue (MB) under solar radiation by $\mathrm{ZrC}$ nanoparticles. Advanced Powder Technology., 2018, 29(9), 2231-2242.

62. Pant, A.; Tanwar, R.; Kaur, B. \& Mandal, U.K. A magnetically recyclable photocatalyst with commendable dye degradation activity at ambient conditions. Scientific reports., 2018, $8,14700$.

63. Wang, J.; Shen, H.; Dai, X.; Li,C.; Shi, W.; Yan, Y.; Graphene oxide as solid-state electron mediator enhanced photocatalytic activities of GO- $\mathrm{Ag}_{3} \mathrm{PO}_{4} / \mathrm{Bi}_{2} \mathrm{O}_{3} \mathrm{Z}$-scheme photocatalyst efficiently by visible-light driven. Materials Technology., 2018, 33(6), 421-432.

64. Saikia, L.; Bhuyan, D.; Saikia, M.; Banajit, M.; Dutta, D.; Sengupta, P., Photocatalytic performance of $\mathrm{ZnO}$ nanomaterials for self sensitized degradation of malachite green dye under solar light. Applied Catalysis A: General., 2015, 490, 42-49.

65. Houas, A.; Lachheb, H.; Ksibi, M.; Elaloui a, E.; Guillard, C.; Herrmann, J., Photocatalytic degradation pathway of methylene blue in water. Applied Catalysis B: Environmental., 2001, 31(2), 145-157. 